\title{
Folic acid and melatonin ameliorate carbon tetrachloride-induced hepatic injury, oxidative stress and inflammation in rats
}

Hossam Ebaid ${ }^{1,2^{*}}$, Samir AE Bashandy ${ }^{1,3}$, Ibrahim M Alhazza ${ }^{1,4}$, Ahmed Rady ${ }^{1}$ and Sultan El-Shehry ${ }^{1}$

\begin{abstract}
This study investigated the protective effects of melatonin and folic acid against carbon tetrachloride (CCl4)induced hepatic injury in rats. Oxidative stress, liver function, liver histopathology and serum lipid levels were evaluated. The levels of protein kinase B (Akt1), interferon gamma (IFN- $\gamma$ ), programmed cell death-receptor (Fas) and Tumor necrosis factor-alpha (TNF-a) mRNA expression were analyzed. CCl4 significantly elevated the levels of lipid peroxidation (MDA), cholesterol, LDL, triglycerides, bilirubin and urea. In addition, CCl4 was found to significantly suppress the activity of both catalase and glutathione (GSH) and decrease the levels of serum total protein and HDL-cholesterol. All of these parameters were restored to their normal levels by treatment with melatonin, folic acid or their combination. An improvement of the general hepatic architecture was observed in rats that were treated with the combination of melatonin and folic acid along with $\mathrm{CCl} 4$. Furthermore, the CCl4-induced upregulation of TNF- $a$ and Fas mRNA expression was significantly restored by the three treatments. Melatonin, folic acid or their combination also restored the baseline levels of IFN- $\gamma$ and Akt1 mRNA expression. The combination of melatonin and folic acid exhibited ability to reduce the markers of liver injury induced by $\mathrm{CCl} 4$ and restore the oxidative stability, the level of inflammatory cytokines, the lipid profile and the cell survival Akt1 signals.
\end{abstract}

Keywords: Hepatic injury-markers, Melatonin, Folic acid, Akt1, Oxidative stress, Anti-inflammatory effects

\section{Introduction}

Carbon tetrachloride (CCl4) is a well-known compound for the production of chemical hepatic injury [1] mediated by metabolites that react with antioxidant enzymes, such as glutathione (GSH), catalase and superoxide dismutase, [2] and increase the level of inflammatory cytokines. Antioxidants exhibit a strong protection against CCl4-induced hepatic toxicity $[3,4]$. Previous studies have shown that melatonin and folic acid are very potent antioxidants that scavenge reactive oxygen species (ROS) [5]. The release of melatonin, a pineal gland hormone [6], is mainly implicated in the regulation of the sleep/wake cycle and the hormonal regulation of sexual development [7]. Melatonin has been found to be more effective in the protection against oxidative damage than other antioxidants, including

\footnotetext{
* Correspondence: hossamebaid@yahoo.com

'Department of Zoology, College of Science, King Saud University, KSA, P.O. Box, 2455, Riyadh 11451, Saudi Arabia

2Department of Zoology, College of Science, El-Minia University, El-Minia, Egypt

Full list of author information is available at the end of the article
}

vitamin E, glutathione and mannitol [8]. However, the circulating levels of melatonin following oral administration can increase both the mRNA levels and the activities of antioxidant enzymes [9]. The administration of melatonin to aged mice was able to inhibit increase the relative expression of pancreatic genes that are involved in inflammation, oxidative stress and apoptosis [10] and decrease the mRNA expression of Tumor necrosis factor-alpha (TNF$\alpha$ ), interleukin-1 $\beta$ (IL-1 $\beta$ ), nuclear factor (NF)- $\mathrm{kB}$ and transcriptional repressor (NKAP) [11]. Melatonin also reduces cytokine levels in surgical neonates [12]. Melatonin prevents hemorrhagic shock-induced liver injury in rats through an Akt-dependent HO-1 pathway [13].

Epidemiological studies have shown that folic acid supplementation can reduce the risk of cardiovascular and hematological diseases [14], neurological and neuropsychiatric disorders [15], neural tube defects [16] and several types of cancer, including cervical, lung, brain, pancreatic, colorectal and breast cancer [17]. The antioxidant activity of folic acid is thought to be involved in
C Biomed Central

(c) 2013 Ebaid et al.; licensee BioMed Central Ltd. This is an Open Access article distributed under the terms of the Creative Commons Attribution License (http://creativecommons.org/licenses/by/2.0), which permits unrestricted use, distribution, and reproduction in any medium, provided the original work is properly cited. 
these effects of folic acid on health [18]. In fact, folic acid has been reported to have an antioxidant effect against ROS and an alleviating role in hyperhomocysteinemia and its associated endothelial dysfunction [19]. Moreover, the anti-inflammatory effect of folic acid is manifested by a decrease in the levels of interleukin and C-reactive proteins [20].

The combination of melatonin and folic acid improves oocyte quality and thus the pregnancy outcome in women with a history of low oocyte quality [21]. In particular, because melatonin and folic acid are very potent antioxidants in the scavenging of ROS, their effects on CCl4-induced hepatic toxicity were investigated in this study. However, no reports are currently available on the protective effect of folic acid alone or in combination with melatonin against the oxidative stress that occurs from CCl4- induced hepatic injury, which is the subject of this study. Folates function as cofactors in the transfer and utilization of carbon groups and therefore play a key role in the biosynthesis of purines and pyrimidines and the regeneration of methionine. The re-methylation of homocysteine to form methionine requires folate, which alters the secretion of melatonin in rats [22]. Therefore, we hypothesized that the combination of folic acid and melatonin would prove useful in the prevention of various liver injuries induced by oxidative stress.

\section{Materials and methods}

\section{Animals and experimental design}

A total of 56 male Wistar rats (Rattus norvegicus) weighing $150-170 \mathrm{~g}(20 \pm 1$ weeks) was obtained from the College of Pharmacy, King Saud University. Throughout the experiment, the animals were housed in polypropylene cages, one for each group of eight animals. They were allowed to acclimatize to the laboratory environment for seven days before the beginning of the experiment. The animals were maintained at $18-22^{\circ} \mathrm{C}$, kept on a 12:12 h light:dark cycle and provided with food and water ad libitum. All animal procedures were conducted in accordance with the standards set forth in the guidelines for the care and use of experimental animals by the Committee for the Purpose of Control and Supervision of Experiments on Animals and the National Institutes of Health. The study protocol was approved by the Animal Ethics Committee of the Zoology Department in the College of Science at King Saud University.

The rats were divided into seven groups, each of which contained eight rats. Group 1 served as the control and only received the vehicle. Group 2 received a single dose of $1 \mathrm{ml} / \mathrm{kg} \mathrm{CCl} 4$ in liquid paraffin (1:1 volume) through an intraperitoneal (IP) injection [23] (inoculated dose was $0.1 \mathrm{ml}$ ). Groups 3 and 4 were pretreated with a daily dose of $2.5 \mathrm{mg} / \mathrm{kg}$ folic acid and $10 \mathrm{mg} / \mathrm{kg}$ melatonin S. $\mathrm{C}$, respectively [24], for 3 weeks before receiving the
CCl4 challenge. Group 5 received the same doses of folic acid as group 3; similarly, Group 6 was treated with the same melatonin treatment protocol as group 4. Group 7 was pre-treated with a combination of folic acid and melatonin for 3 weeks before $\mathrm{CCl} 4$ challenge. The samples were collected 2 days after the injection of $\mathrm{CCl} 4$.

\section{Chemicals}

The chemicals 5,5-dithiobis-2-nitrobenzoic acid (DTNB), dihydrogen phosphate, trichloroacetic acid, carbon tetrachloride, and thiobarbituric acid were purchased from Merk Company, Darmstadt, Germany. Melatonin was obtained from MPBiomedicals, LLC, Llkirch, France. Folic acid was purchased from Sigma Chemical Company, Louis, MO, USA.

\section{Blood and liver samples}

Two days after treatment, the animals from all groups were autopsied under light ether anesthesia. The blood was drawn from the animals by puncturing the retroorbital venous sinus with capillary tubes until killing. The blood was collected in heparin-coated centrifuge tubes, centrifuged at $200 \times g$ for 10 minutes, then plasma was separated in Eppendorf tubes and stored at $-30^{\circ} \mathrm{C}$. Whole blood was used for the determination of the level of hydroperoxide, whereas separated plasma was used to determine the level of liver enzymes, the amount of total protein and the lipid profile.

The liver was removed, washes with saline and cut into two parts, one part was used for the histological study and the other part was used for the assessment of lipid peroxidation (MDA), GSH and catalase. The hepatic tissues were homogenized (Automated homogenizer, IKA, T25D, Germany) in $10 \mathrm{mM} \mathrm{KCl}$ in $1.15 \%$ phosphate buffer and ethylenediamine tetraacetic acid (EDTA; pH 7.4) and centrifuged at $5000 \times \mathrm{g}$ for $10 \mathrm{~min}$. The supernatant was used to assay the level of thiobarbituric acid reactive substances (TBARS) and to estimate the amount of GSH and catalase.

\section{Biochemical analysis \\ Estimation of lipid peroxides}

The blood hydroperoxide level was evaluated using the free radical analytical system (Iran, Parma, Italy), which is a colorimetric test that takes advantage of the ability of hydroperoxides to generate free radicals after reacting with some transitional metals. In this test, a colored complex appears when buffered chromogenic substances are added to a solution that contains hydroperixodes. The amount of complex that was formed can then be measured by a spectrophotometer. The lipid peroxidation level, or the amount of TBARS in the liver, was measured by a method described by Ohkawa, et al. [25]. The liver tissue was homogenized in ice-cold $0.15 \mathrm{M}$ 
$\mathrm{HCl}(10 \%)$ and the absorbance was read at $532 \mathrm{~nm}$. Using 1,1,3,3-tetramethoxypropane as the standard, the absorbance was used to determine the concentration of TBARS, which was expressed as nm of MDA per mg protein.

\section{Assay of hepatic reduced glutathione}

The reduced form of glutathione was determined using DTNB as the coloring reagent and following the method described by Moron et al. [26]. The absorbance was read at $412 \mathrm{~nm}$ using a spectrophotometer and the GSH concentration was calculated from a standard curve.

\section{Determination of hepatic catalase}

The level of catalase activity was estimated in the liver homogenate by the method described by Aebi [27]. The specific activity of catalase is expressed in units of moles of $\mathrm{H} 2 \mathrm{O} 2$ consumed $/ \mathrm{min} / \mathrm{mg}$ of protein. The difference in the absorbance at $240 \mathrm{~nm}$ per unit time was used to determine the catalase activity.

\section{Liver function tests and lipid profile}

The levels of AST, ALT, ALP, bilirubin, LDH, cholesterol, triglycerides, LDL, HDL, protein, and urea were measured in the plasma samples obtained from all the groups. The measurements were performed in accordance with the manufacturer protocols of the Bio Merieux kits, France. The amounts of AST, ALT and ALP were determined kinetically, whereas the other proteins were evaluated by colorimetry. The intensity of coloration was measured using the UV/Visible-Model-80-2106-00 spectrophotometer, Pharmacia Biotech, Cambridge, England.

\section{Histological study}

The liver sample from each animal was processed using light microscopy. The tissue sections were fixed in $10 \%$ neutral buffered formalin and embedded in paraffin. The paraffin sections were then stained with hematoxylineosin $(\mathrm{H} \& \mathrm{E})$. Mallory Trichrome was used for detecting the collagen deposition in the hepatic tissue. The degree of liver damage was examined blindly using a Leica DMRB/E light microscope (Heerbrugg, Switzerland).

\section{RNA extraction and cDNA synthesis}

The total RNA from the liver tissue homogenates was isolated using TRIzol reagent (Invitrogen ${ }^{\circledR}$ ). The isolation was performed according to the manufacturer's instructions and quantified by measuring the absorbance at $260 \mathrm{~nm}$. The cDNA synthesis was performed using the High-Capacity cDNA reverse transcription kit (Applied Biosystems ${ }^{\circledR}$ ) according to the manufacturer's instructions. A total of $1.5 \mu \mathrm{g}$ of total RNA from each sample was added to a mixture of $2.0 \mu \mathrm{l}$ of $10 \mathrm{x}$ reverse transcriptase buffer, $0.8 \mu \mathrm{l}$ of $25 \mathrm{x}$ dNTP mix (100 mM), $2.0 \mu \mathrm{l}$ of $10 \mathrm{x}$ reverse transcriptase random primers, $1.0 \mu \mathrm{l}$ of MultiScribe reverse transcriptase, and $3.2 \mu \mathrm{l}$ of nuclease-free water. The final reaction mixture was kept at $25^{\circ} \mathrm{C}$ for $10 \mathrm{~min}$, heated to $37^{\circ} \mathrm{C}$ for $120 \mathrm{~min}$, heated to $85^{\circ} \mathrm{C}$ for $5 \mathrm{~s}$, and then cooled to $4^{\circ} \mathrm{C}$.

\section{Quantification of mRNA expression by real-time polymerase chain reaction}

The quantitative analysis of the level of mRNA expression of the target genes was achieved by RT-PCR. The cDNA from the above preparation was subjected to PCR amplification using 96-well optical reaction plates in the $\mathrm{ABI}$ Prism 7500 System (Applied Biosystems ${ }^{\circledR}$ ). The 25- $\mu \mathrm{l}$ reaction mixture in each well contained $0.1 \mu \mathrm{l}$ of $10 \mu \mathrm{M}$ forward primer and $0.1 \mu \mathrm{l}$ of $10 \mu \mathrm{M}$ reverse primer for a final concentration of $40 \mu \mathrm{M}$ of each primer, $12.5 \mu \mathrm{l}$ of SYBR Green Universal Mastermix (Applied Biosystems ${ }^{\circledR}$ ), $11.05 \mu \mathrm{l}$ of nuclease-free water, and $1.25 \mu \mathrm{l}$ of the cDNA sample. The primers used in the current study were chosen from the PubMed database (pubmed.com) (Table 1). The RT-PCR data were analyzed using the relative gene expression method, as described by the Applied Biosystems ${ }^{\circledR}$ User Bulletin No. 2. The data are therefore presented as the fold change in gene expression normalized to the endogenous reference gene and relative to a calibration gene.

\section{Statistical analysis}

The statistical analysis was performed using the MINITAB software (MINITAB, State College, PA, Version 13.1, 2002). The data from the experiments were tested for normality using the Anderson Darling test and for variance homogeneity prior to any further statistical analysis. The data were normally distributed with homogeneous variances. Thus, the one-way ANOVA statistical measure was used to determine overall effect of each treatment. This measure was supplemented by individual comparison between the different treatments using Tukey's method for pairwise comparisons. The results

Table 1 Sequences of primer and probes of quantitative RT-PCR

\begin{tabular}{ll}
\hline Primer & Sequence \\
\hline Fas & F: CTGCCTCTGGTGCTTGCTGGC \\
& R: ACCCCACCCCCTTCTCCCAATTC \\
AKt1 & F: ACGCCGCCTGATCAAGTCTCC \\
& R: TGACGGACAGCGGGAGAGGG \\
IFN- $-\mathrm{F}:$ TCTGGGCTTCTCCTCCTGCGG & R: GGCGCTGGACCTGTGGGTG \\
& F: GCGGAGTCCGGGCAGGTCTA \\
TNF-a & R: GGGGGCTGGCTCTGTGAGGA \\
\hline
\end{tabular}


were expressed as arithmetic mean $(\mathrm{M}) \pm$ standard deviation (SD). Only statistically significant differences, with $\mathrm{P}<0.05$, that were found between a treatment group and the control and between a treatment group and the $\mathrm{CCl}_{4}$ group were considered.

\section{Results}

Effects of melatonin and folic acid on $\mathrm{CCl} 4$-induced oxidative stress

The results revealed that $\mathrm{CCl} 4$ significantly elevated both the concentration of hydroperoxide and the amount of lipid peroxidation. Melatonin, folic acid and their combination were found to significantly reduce this high concentration of hydroperoxide, although it was still significantly higher than that of the control group. Interestingly, the amount of lipid peroxidation was restored to the normal baseline concentration observed in the control group by these three treatments (Table 2). We showed that glutathione, the most important antioxidant enzyme, was significantly decreased by $\mathrm{CCl} 4$ challenge. However, the concentration of glutathione in animals treated with melatonin, folic acid and their synergic combination was four to six-fold higher $(p<0.05)$ than the concentration of glutathione measured in the CCl4-treated group. Furthermore, these three treatments restored the concentration of catalase activity to values close to that observed in the control group (Table 2).

\section{Effect of melatonin and folic on CCl4-induced TNF-a Akt1, Fas and IFN- $\gamma$ mRNA expression}

The expected CCl4-induced hepatocytotoxic effects were confirmed by the significantly elevated apoptosis receptor Fas and TNF- $\alpha$ mRNA expression levels, but either melatonin, folic acid or their combination down regulated these expression levels to those observed in the control group (Table 2). In addition, these three treatments were found to significantly upregulate the expression of the Akt1 and IFN- $\gamma$ mRNA compared to the $\mathrm{CCl} 4$ group. This restoration of the Akt1 and IFN- $\gamma$ gene expressions in the animals treated with the combination of melatonin and folic acid was superior to that observed in the animals treated with only one of these compounds.

\section{Biochemical analysis and Histopathological examination Effects of melatonin and folic acid on CCl4-induced liver enzyme concentrations}

The results presented in Table 3 show that $\mathrm{CCl} 4$ was found to significantly elevate the levels of ALP, ALT, LHD and AST to concentrations that are two-, ten-, two and a half-, three and a half-, six- and thirty-fold their normal values, respectively. In addition, the combination of melatonin and folic acid was found to significantly restore the concentrations of both ALP and LDH to their baseline concentrations. Although the individual treatments with melatonin or folic acid did not normalize the concentrations of ALT and AST to the values observed in the control group, they did significantly decrease the concentrations of these enzymes compared to that observed in the CCl4-group (Table 3).

\section{Effect of combination of melatonin and folic acid on $\mathrm{CCl} 4$ induced lipid profile}

The cardiovascular risk indices were significantly elevated as a result of CCl4-induced hepatic injury, and treatment with melatonin and folic acid restored these indices. In addition, we found that $\mathrm{CCl} 4$ significantly elevated the concentrations of total cholesterol, LDL cholesterol and triglycerides. However, melatonin, folic acid and the combination of these two treatments significantly restored the concentration of these parameters to that measured in the control group. Interestingly, HDL was found to be significantly reduced by the $\mathrm{CCl} 4$ challenge, a decrease that was not observed when the animals received any of the three treatments (Table 3 ).

\section{Effects of melatonin and folic acid on CCl4-induced concentration of total protein, bilirubin and urea} The results revealed that $\mathrm{CCl} 4$ significantly decreased the concentration of total protein in the serum.

Table 2 Concentrations of oxidative stress parameters and relative mRNA expression of TNF- $\alpha$, AKT1, Fas and IFN- $\gamma$ induced in the different groups

\begin{tabular}{llllllll}
\hline Parameters & Control group & CCL4 & Me & CCL4+Me & Fo & CCL4+Fo & CCL4+Me + Fo \\
\hline Blood Hydroperoxide (mg/100 ml) & $24 \pm 5.0$ & $44.5^{*} \pm 6.2$ & $21.5 \pm 4.3$ & $32.1^{*} \pm 4.2$ & $21.8 \pm 3.0$ & $30.6 \pm 6.3$ & $27 \pm 5.0$ \\
Hepatic MDA (nmol/mg protein) & $3 \pm 0.7$ & $5.6^{*} \pm 0.9$ & $2.1 \pm 0.8$ & $4^{*} \pm 0.7$ & $2.4 \pm 0.7$ & $4.4^{*} \pm 0.9$ & $2.1 \pm 0.6$ \\
Hepatic GSH ( $\mathrm{mmol} /$ g liver tissue) & $12.2 \pm 1.8$ & $5^{*} \pm 1.8$ & $25.7^{*} \pm 7.8$ & $14.7 \pm 5.0$ & $28.6^{*} \pm 5.8$ & $21.7^{*} \pm 5.0$ & $21.2^{*} \pm 5.1$ \\
Catalase (Unit/mg protein) & $14.4 \pm 1.8$ & $7.9^{*} \pm 1.0$ & $16.3 \pm 1.8$ & $11.5 \pm 2.8$ & $16 \pm 2.7$ & $10^{*} \pm 0.9$ & $14 \pm 1.5$ \\
Relative expression of TNF-a mRNA & $1.8 \pm 0.8$ & $5.6^{*} \pm 0.9$ & $1.6 \pm 0.5$ & $3.3^{*} \pm 0.7$ & $2.1 \pm 0.8$ & $3.2^{*} \pm 0.7$ & $1.7 \pm 0.5$ \\
Relative expression of Akt1 mRNA & $5.7 \pm 1.1$ & $1.8^{*} \pm 0.5$ & $15.2^{*} \pm 2.7$ & $5.0 \pm 1.3$ & $17^{*} \pm 1.8$ & $5.0 \pm 1.6$ & $7.0 \pm 1.8$ \\
Relative expression of Fas mRNA & $0.9 \pm 0.3$ & $10.1^{*} \pm 0.9$ & $0.8 \pm 0.45$ & $8.2^{*} \pm 1.2$ & $0.78 \pm 0.2$ & $5.5^{*} \pm 0.2$ & $2.5^{*} \pm 0.7$ \\
Relative expression of IFN- $\gamma$ mRNA & $18.5 \pm 7.2$ & $7.0^{*} \pm 2.2$ & $17.5 \pm 6.0$ & $8.8^{*} \pm 0.9$ & $34.2^{*} \pm 4.4$ & $14.6 \pm 2.6$ & $20.2 \pm 3.0$
\end{tabular}

The results are expressed as $\mathrm{M} \pm \mathrm{SD}$. * shows a statistically significant difference $(\mathrm{P}<0.05)$ in the pairwise comparison between a treatment group and the control. 
Table 3 Plasma concentrations of liver enzymes, lipids, total protein, bilirubin and urea from the control and the different groups

\begin{tabular}{llllllll}
\hline Parameters & Control group & CCL4 & Me & CCL4+Me & Fo & CCL4+Fo & CCL4+Me + Fo \\
\hline ALP (U/L) & $232.6 \pm 33.5$ & $418.3^{*} \pm 67$ & $238.6 \pm 62$ & $279.1 \pm 34$ & $234.7 \pm 43$ & $267.3 \pm 61$ & $228 \pm 35$ \\
ALT (U/L) & $27 \pm 3.8$ & $369^{*} \pm 106$ & $29 \pm 3.0$ & $293.5^{*} \pm 34$ & $22.7 \pm 1.1$ & $205.5^{*} \pm 77$ & $156.5^{*} \pm 62$ \\
AST (U/L) & $48.7 \pm 4.0$ & $369^{*} \pm 91$ & $42.1 \pm 4.8$ & $251^{*} \pm 48$ & $41 \pm 7.2$ & $288.7^{*} \pm 112$ & $237.7^{*} \pm 71$ \\
LDH (U/L) & $192.3 \pm 63$ & $576^{*} \pm 221$ & $165.3 \pm 47$ & $317.3 \pm 110$ & $178.6 \pm 43$ & $363.3 \pm 130$ & $337.5 \pm 143$ \\
Cholesterol (mg/100 ml) & $57.7 \pm 8.0$ & $8^{*} \pm 14$ & $53 \pm 6.0$ & $59 \pm 9.0$ & $61 \pm 5.0$ & $76^{*} \pm 14$ & $57 \pm 8.6$ \\
LDL-C (mg/100 ml) & $33 \pm 6.6$ & $50^{*} \pm 15$ & $37 \pm 6.0$ & $38 \pm 2.3$ & $36 \pm 5.7$ & $44^{*} \pm 5.0$ & $36 \pm 6.0$ \\
HDL (mg/100 ml) & $31 \pm 5.5$ & $10^{*} \pm 4.9$ & $32 \pm 5.6$ & $16^{*} \pm 7.0$ & $30 \pm 5.4$ & $24 \pm 7.3$ & $27 \pm 6.3$ \\
Triglycerides (mg/100 ml) & $66 \pm 4.3$ & $125^{*} \pm 10$ & $51 \pm 6.0$ & $82^{*} \pm 7.0$ & $65 \pm 6.2$ & $70 \pm 6.2$ & $66 \pm 3.2$ \\
Plasma Protein g/100 ml & $7.7 \pm 0.6$ & $5.5^{*} \pm 0.5$ & $7.3 \pm 0.9$ & $5.8^{*} \pm 0.35$ & $6.7 \pm 0.7$ & $5.7^{*} \pm 0.7$ & $6.7 \pm 0.7$ \\
Bilirubin Mg/100 ml & $0.246 \pm 0.08$ & $0.468 \pm 0.17$ & $0.226 \pm 0.04$ & $0.324 \pm 0.06$ & $0.266 \pm 0.06$ & $0.42^{*} \pm 0.1$ & $0.355 \pm 0.07$ \\
Urea Mg/100 ml & $40.6 \pm 7.3$ & $55.5^{*} \pm 10$ & $33.6 \pm 5.9$ & $55^{*} \pm 9.5$ & $50.8 \pm 7.0$ & $48.5 \pm 3.0$ & $37.6 \pm 5.4$ \\
\hline
\end{tabular}

The results are expressed as the $\mathrm{M} \pm \mathrm{SD}$. * shows a statistically significant difference $(P<0.05)$ in the pairwise comparison between a treatment group and the control.

Treatment with either melatonin or folic acid individually failed to restore the normal concentration of total protein. However, the synergistic combination of folic acid and melatonin was uniquely able to restore the concentration of total protein to a value that is close to that measured in the control group. Unlike its effect on the total protein concentration, the amounts of bilirubin and urea in the serum of CCl4-challenged rats was two and one and a half-fold higher than the concentration in the serum of control rats. We generally observed that the treatments with melatonin or with the combination of melatonin and folic acid were better able to restore the concentrations of these two parameters than treatment with folic acid (Table 3).

\section{Effect of combination of melatonin and folic acid on the histology of liver}

An increased number of mitotic figures, vacuolated hepatocytes, and eosinophilic hepatocytes characterized the histological sections of the CCl4-challenged group. The liver sections obtained from CCl4-challenged rats that were treated with folic acid showed a large number of mitotic figures, which were not present in the liver sections obtained from CCl4-challenged rats that were treated with melatonin. In addition, the combined treatment of folic acid and melatonin resulted in an improvement in the general hepatic architecture (Figure 1).

Histopathological changes of collagen deposition occurred in CCl4-challenged rats and prevention by the treatment with melatonin and folic acid are showed in Figure 2. The tissues of rats treated with $\mathrm{CCl} 4$ revealed extensive accumulation of connective tissue resulting in formation of continuous interlobular septa, noticeable alterations and dilations in the central vein and pronounced inflammation as compared to the normal control (Figure 2B, 2C). The group challenged with $\mathrm{CCl} 4$ and treated with melatonin and folic acid resulted in less destruction of the liver architecture without fibrosis and moderate inflammation (Figure 2D).

\section{Discussion}

This study investigated the capability of folic acid, melatonin or the combination of these two compounds to protect against $\mathrm{CCl} 4$-induced hepatotoxicity. Our findings confirmed the previous observations that melatonin [28] and folic acid [29] effectively reduce oxidative stress, restore the normal concentrations of anti-oxidant enzymes, and exhibit antihyperlipidemic activity. In addition, the antioxidant activity of natural products has a number of beneficial effects in the treatment of various types of diseases [30].

The hepatotoxicity of $\mathrm{CCl} 4$ includes the production of free radicals and the activation of Kupffer cells and macrophages, which generate inflammatory and profibrogenic mediators. The overproduction of free radicals is the initial step in a chain of events that eventually leads to membrane lipid peroxidation and ultimately to cellular apoptosis and necrosis [31]. The potential mechanisms of chemical-induced liver apoptosis include an increase in cytokine concentrations and/or oxidative stress [32]. In addition, lipid peroxidation, a ROSmediated mechanism, has been implicated in the pathogenesis of various liver injuries and the subsequent liver fibrogenesis that is observed in experimental animals [33].

We found that the concentration of MDA and hydroperoxide, which are indices of oxidative stress, were elevated in CCl4-challenged rats. However, decreased concentrations of these two compounds were found in the liver tissues of those CCl4-rats that were treated 


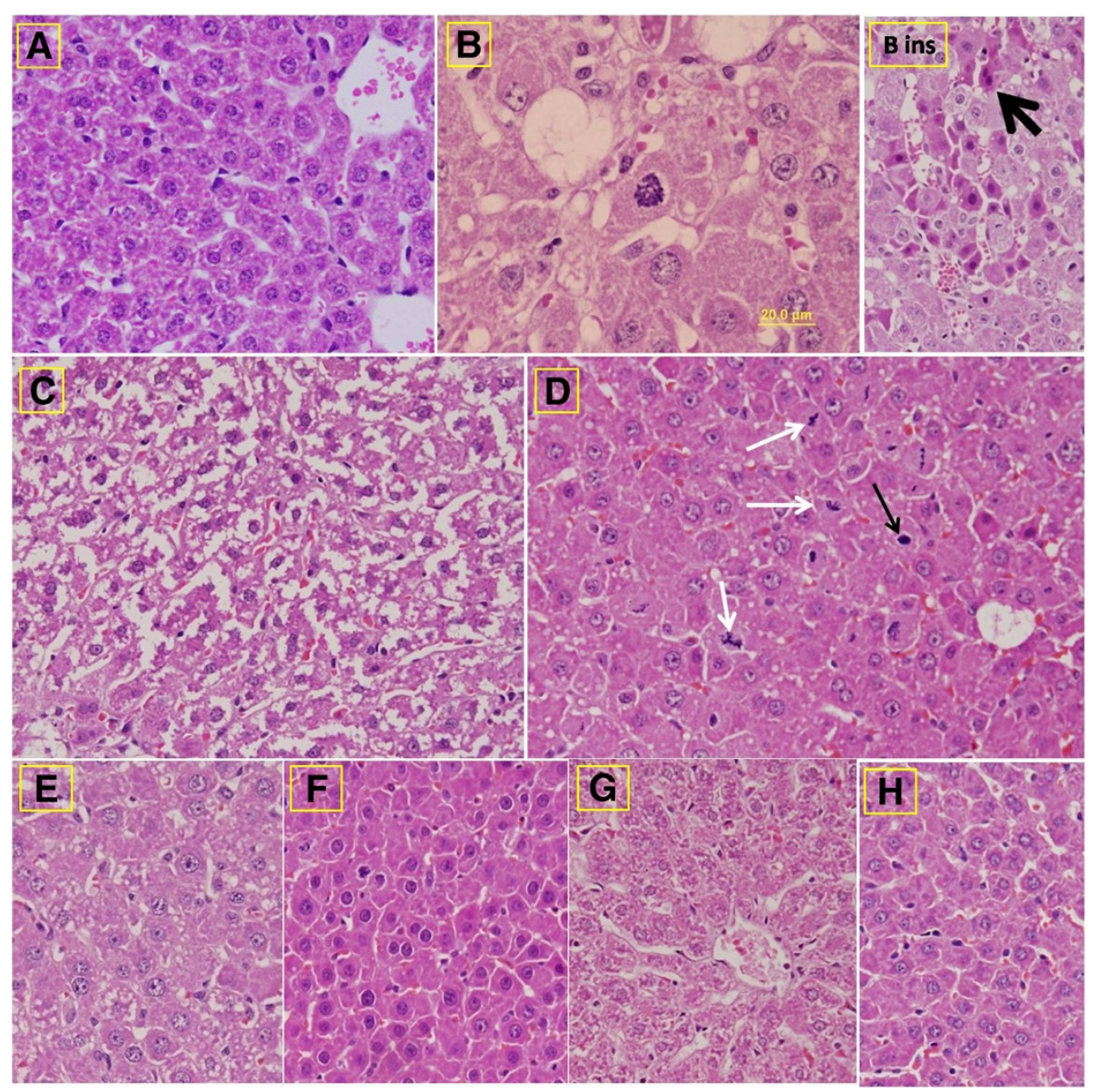

Figure 1 Photomicrographs for liver sections of the different groups A: Photomicrograph of a control liver section showing the normal histological architecture of hepatic tissues (H\&E stain, 400x). B: The histological features of a representative liver section from CC/4-treated rats (the sections from four rats in this group were investigated), which shows the increased number of mitotic figures (arrow) and the clear vacuolation of the hepatocytes (H\&E stain, 1000x). Insert: In addition to the mitotic figures, eosinophilic hepatocytes (arrow) were detected in sections from two of the CCl4-treated rats in this group (H\&E stain, 400x). C: A representative liver section from CCl4 + Me-treated rats (H\&E stain, 400x) was characterized by the absence of the mitotic figures. However, vacuolated hepatocytes and abnormal damaged hepatic tissues were still found. D: A representative liver section from CCl4 + Fo-treated rats shows many mitotic figures (white arrows), which resemble those detected in the liver sections from CCl4-treated rats. A number of pyknotic nuclei were detected in the sections from this group (H\&E stain, 400x). E: A representative liver section from $\mathrm{CCl} 4+\mathrm{Me}+$ Fo-treated rats, which exhibit an improvement of the general hepatic architecture (sections from five rats in this group were investigated) (H\&E stain, 400x). F: A liver section from the group of CCl4 + Me + Fo-treated rats that shows little improvement (this was observed in the sections from two of the rats) (H\&E stain, 400x). G: A representative liver section from Fo-treated rats, which shows the general hepatic architecture with a small amount of side effects, such as faintly stained nuclei (H\&E stain, 400x). H: A representative liver section from Me-treated rats, which shows the general hepatic architecture with narrow hepatic sinusoids and a large number of hepatocytes (H\&E stain, 400x).

with either melatonin, folic acid or the combination of melatonin and folic acid, which suggests that these compounds can effectively protect against lipid peroxidation. Melatonin exerts antioxidant protection in different cell organelles, both in vitro and in vivo [34]. The body has an effective defense mechanism to prevent and neutralize damage that is induced by free radicals. These enzymes constitute a mutually supportive team of defense against ROS [35]. Melatonin and folic acid were found to significantly restore the normal concentrations of GSH and the catalase activity. The catalase enzyme, which exists in all aerobic cells, is a hemeprotein that metabolizes the decomposition of $\mathrm{H} 2 \mathrm{O} 2$ to form oxygen and water. GSH acts as a non-enzymatic anti-oxidant that reduces the amount of $\mathrm{H} 2 \mathrm{O} 2$, hydroperoxides and xenobiotic toxicity [36]. The significant decrease of hydroperoxide in the blood and hepatic tissues confirmed that the pre-treatment with folic acid and melatonin could effectively protect against the hepatic lipid peroxidation that is induced by $\mathrm{CCl} 4$. The anti-oxidant activity and antilipidemic effects of melatonin may enhance the modulation of blood pressure and most likely 

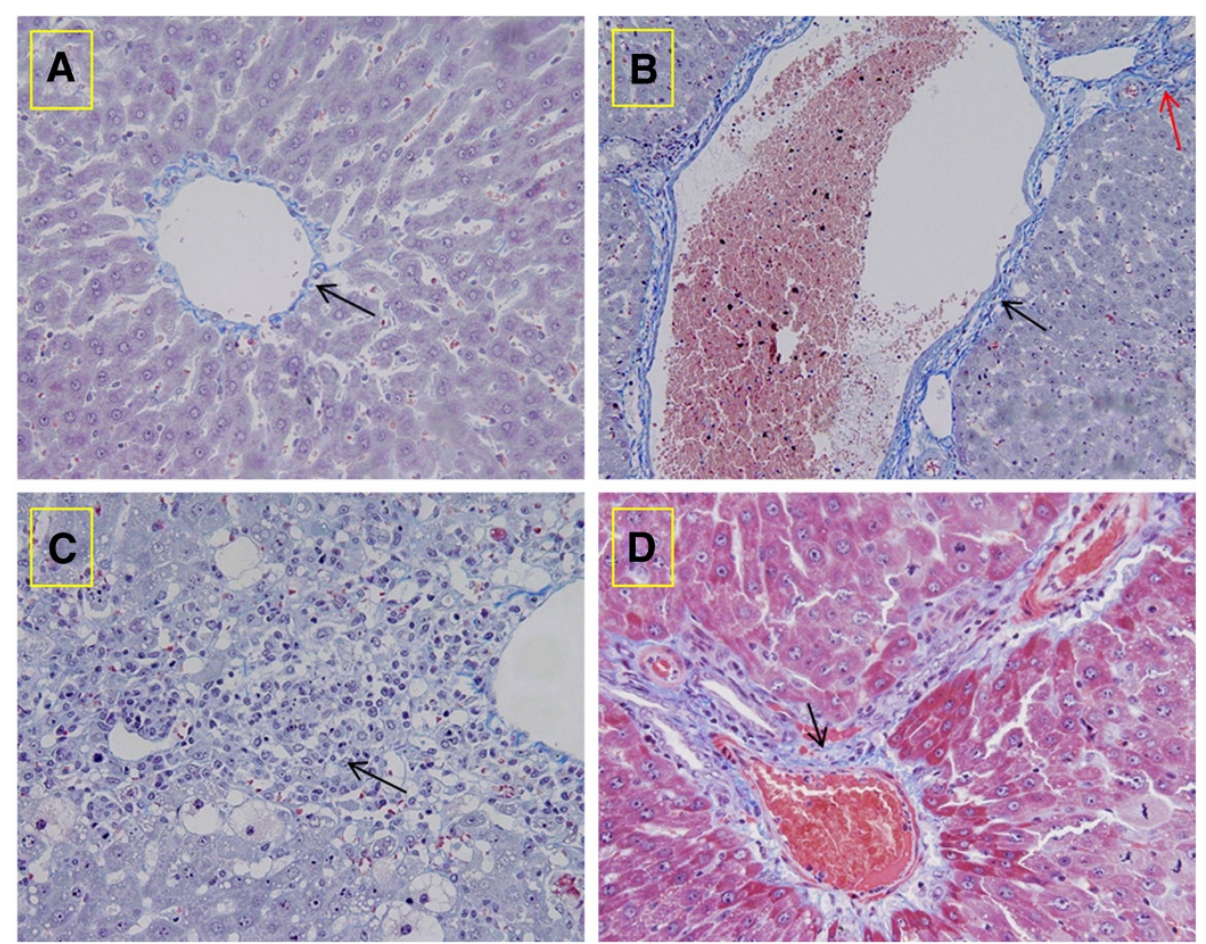

Figure 2 Histological assessment of liver fibrosis in CCl4-treated rats and the effects of the combination of melatonin and folic acid on collagen deposition. The extent of matrix deposition (arrow) was measured by Masson's trichrome staining of liver tissue sections from control animals (A: 400x), CCl4-treated rats (black arrow: collagen of the very dilated central vein; red arrow: the interlobular collagen deposition) (B: 200x), CCl4-treated rats to show the inflammatory cells (C: 400x) and the rats receiving melatonin and folic acid (black arrow: collagen of the central vein) (D: 400x).

play the most important role in the amelioration of the damage to the target organ [37]. GSH is a crucial determinant for cell survival or death in oxidative stress conditions [38] and, thus, GSH is critical in reducing the toxic effects of $\mathrm{CCl} 4$. Moreover, the increase in hepatic GSH concentrations in rats treated with either folic acid, melatonin or their combination may be due to an increase in the amount of GSH synthesis or regeneration.

ROS upregulates NF- $\mathrm{kB}$, which is required for the induction of pro-inflammatory cytokines, such as IL-1ß, TNF- $\alpha$ and IL-6 [39]. TNF- $\alpha$ is a key mediator of the immune and inflammatory responses and controls the expression of the inflammatory gene network. Therefore, the overproduction of TNF- $\alpha$ contributes significantly to the pathological complications observed in many inflammatory diseases; for example, pro-inflammatory cytokines can increase the risk of schizophrenia [40]. Similarly, hepatic injury is associated with the upregulation of TNF- $\alpha$ gene expression that was observed in the $\mathrm{CCl} 4$ group; this result is therefore in accordance with previous studies [41]. Consequently, the overproduction of TNF- $\alpha$ contributed to the manifestation of the systemic inflammatory response and ultimately to the development of organ failure.
We found that the upregulation of TNF- $\alpha$ expression was accompanied by the upregulation of the Fas genes in CCl4-induced liver injury. The Fas protein is a type I membrane receptor that belongs to the TNF-receptor superfamily. Mita et al. [42] found that the expression of FasL by macrophages plays a role in their pathogenesis.

In the present study, Fas mRNA expression was significantly upregulated in CCl4- injected rats. Similarly, Zhang et al. [43] found that the expression of Fas is increased in CCl4-induced liver fibrosis. Activation of the Fas receptor by the FasL induces apoptosis via the activation of the caspase cascade [44]. Therefore, the upregulation of both TNF- $\alpha$ and Fas clearly explains the hepatic tissue damage and dysfunction that was observed in the $\mathrm{CCl} 4$ group. Furthermore, hepatic injury in rats leads to elevations of serum AST and ALT and an increased incidence and severity of histopathological hepatic lesions. The present study revealed a significant increase in the concentrations of AST, ALT and ALP upon exposure to $\mathrm{CCl} 4$, which indicates considerable hepatocellular injury. In addition, an increase in serum AST and ALT concentrations by $\mathrm{CCl} 4$ has been attributed to hepatic structural damage because these entities are normally localized to the cytoplasm and are only 
released into the circulatory system after cellular damage has occurred [45].

The oxidative stability that is induced by the combination of melatonin and folic acid may mediate a downregulation of NF- $\mathrm{KB}$ activation, which results in the suppression of the inflammatory cascade and the low concentrations of TNF- $\alpha$ that were observed. Thus, the hepatic injury markers were significantly retarded in the animals that received any of these treatments. In fact, folic acid and melatonin significantly attenuated the increased concentrations of the serum liver enzymes that were induced by $\mathrm{CCl} 4$ and therefore led to the subsequent restoration of these to normal concentrations. The effect of folic acid and melatonin was further confirmed through histopathological examinations. It was found that pre-treatment with the combination of melatonin and folic acid had broad anti-inflammatory effects and attenuated the allergic inflammation in the CCl4challenged rats. This amelioration of the hepatic tissues by melatonin and folic acid seemed to be mediated by the inhibition of oxidative stress and therefore the suppression of NF- $\mathrm{kB}$, the key regulator of inflammatory production, which results in the decreased production of pro-inflammatory cytokines.

The Akt1 signal is critical for cell survival that is triggered by growth factors, the extracellular matrix, and other stimuli [46]. Therefore, there is impaired Akt and eNOS activation in cirrhotic livers [47]. We found a downregulation of Akt1 gene expression in CCl4challenged rats. The concentration of Akt1 mRNA expression was markedly restored in CCl4-rats that were pretreated with the combination of melatonin and folic acid. Previous studies have shown that Myr-Akt gene therapy can restore Akt activation and NO production in cirrhotic livers, which suggests that this therapy may be helpful in treating portal hypertension [47]. The restorative capacity of melatonin and folic acid was also confirmed in the complete restoration of the IFN- $\gamma$ mRNA expression to normal concentrations. The proteins EMSY and BRAC2 repress a number of IFN-stimulated genes; however, an Akt1-dependent pathway contributes to the full activation of IFN-stimulated genes by relieving this repression [48]. Similar data establishes that Akt activity is essential for the upregulation of key IFN- $\alpha$ - and IFN- $\gamma$-inducible proteins, which have important functional consequences in the induction of IFN responses [49]. In addition, the retrovirusmediated expression of activated Akt in primary $\mathrm{T}$ cells from CD28-deficient mice is capable of selectively restoring the production of IL-2 and IFN- $\gamma$ [50]. We proved that the activation and upregulation of Akt1 was accompanied by an improvement in the biomarkers of hepatic damage, the histological architecture and liver function.

We confirmed the hypolipidemic effect of melatonin and folic acid in CCl4-treated rats, which was manifested by the low concentrations of cholesterol, triglycerides, and LDL and the increased HDL concentrations. Similar findings were also reported for other experimental models, which observed a decline in LDL and total cholesterol and an increase in HDL concentrations in animals treated with melatonin [51]. This effect may be related to the enhancement of the catabolism of cholesterol to form bile acids [51] and the inhibition of cholesterol synthesis and LDL receptor activity [52].

HDL plays an essential role in the transport of cholesterol to the liver for excretion into bile acids [53], which are cytoprotective in hepatocytes because of their ability to activate phosphatidylinositol-3-kinase and its downstream signal Akt [54]. We confirmed the upregulation of the Akt1 signal by the combination of melatonin and folic acid. The combination treatment was better able to restore the elevated concentrations of cholesterol, triglycerides and inflammatory indicators than the individual treatments. A significant increase in the arterial elasticity index, a significant improvement in glucose and lipid metabolism, and a significant increase in HDL cholesterol have also been observed in patients treated with anti-oxidants [55]. Additionally, the beneficial effect of anti-oxidants on LDL oxidation has been previously demonstrated [56].

Our findings provide evidence of the potential antioxidant and anti-inflammatory effects of melatonin and folic acid. This combination restored normal oxidative stress concentrations, which might inhibit NF- $\mathrm{kB}$ and thus downregulate TNF- $\alpha$ and Fas mRNA expression. In addition, melatonin and folic acid markedly upregulated the cell survival signal, Akt1, and the IFN- $\gamma$ concentrations. Furthermore, the restoration of the survival signaling genes that was induced by melatonin and folic acid also resulted in significant improvements to the liver function and the histological architecture. There are currently no data on the treatment of $\mathrm{CCl} 4$-induced hepatic injury with melatonin and folic acid that would indicate whether this intervention has a significant clinical impact. We have elucidated a potential role for these substances in the treatment of hepatic injury that needs to be intensively investigated in future research that focuses on patient oriented outcomes.

\section{Abbreviations}

ALT: Alanine Aminotransferase; AST: Aspartate aminotransferase; ALP: Alkaline phosphatase; Fas: Programmed cell death-receptor; LDH: Lactate

dehydrogenase; MDA: Malondialdehyde; ROS: Reactive Oxygen Species; Akt1: Protein kinase B; IFN- $\gamma$ : Interferon gamma; IL: Interleukin; TNF-a: Tumor necrosis factor-alpha.

\section{Competing interest}

There was no conflict of interest for any of the authors of this paper.

\section{Authors' contributions}

HE designed the study, described histological changes, prepared figures, drafted the manuscript and performed the statistical analysis. SB designed 
the study and was responsible of the animal model, the biochemical investigations and drafted the manuscript. IA was responsible for the revision of the manuscript in the final form. AR and SE were participated biochemical investigations. All authors read and approved the final manuscript.

\section{Acknowledgment}

The Authors extend their appreciation to the Deanship of Scientific Research at king Saud University for funding the work through the research group project No. RGPVPP-028.

\section{Author details}

${ }^{1}$ Department of Zoology, College of Science, King Saud University, KSA, P.O. Box, 2455, Riyadh 11451, Saudi Arabia. ${ }^{2}$ Department of Zoology, College of Science, El-Minia University, El-Minia, Egypt. ${ }^{3}$ Department of Pharmacology, National Research Center, Cairo, Egypt. ${ }^{4}$ Fetal Programming of Disease Research Chair, King Saud University, KSA, Riyadh, Saudi Arabia.

Received: 29 September 2012 Accepted: 22 January 2013

Published: 3 February 2013

\section{References}

1. Brattin WJ, GlendeJr EA, Recknagel RO: Pathological mechanisms in carbon tetrachloride hepatotoxicity. J Free Radic Biol Med 1985, 1:27-38.

2. Rikans LE, Hornbrook KR, Cai Y: Carbon tetrachloride hepatotoxicity as a function of age in female Fischer 344 rats. Mech Ageing Dev 1994, 76:89-99.

3. Sheweita SA, El-Gabar MA, Bastawy M: Carbon tetrachloride changes the activity of cytochrome $\mathrm{P} 450$ system in the liver of male rats: role of antioxidants. Toxicology 2001, 169:83-92.

4. Sagai M, Tappel Al: Effect of vitamin E on carbon tetrachlorideinduced lipid peroxidation as demonstrated by in vivo pentane production. Toxicology Lett. 1978, 2:149-155.

5. Letelier ME, Jara-Sandoval J, Molina-Berríos A, Faúndez M, Aracena-Parks $P$, Aguilera F: Melatonin protects the cytochrome P450 system through a novel antioxidant mechanism. Chem Biol Interact 2010, 185:208-214.

6. Ackermann $\mathrm{K}$, Stehle $\mathrm{JH}$ : Melatonin synthesis in the human pineal gland: advantages, implications, and difficulties. Chronobiol Int 2006, 23:369-379.

7. Simonneaux V, Ribelayga C: Generation of the melatonin endocrine message in mammals: a review of the complex regulation of melatonin synthesis by norepinephrine, peptides, and other pineal transmitters. Pharmacol Rev 2003, 55:325-395.

8. Reiter RJ, Tan DX, Mayo JC, Sainz RM, Leon J, Czarnocki Z: Melatonin as an antioxidant: biochemical mechanisms and pathophysiological implications in humans. Acta Biochim Pol 2003, 50:1129-1146.

9. Rodriguez C, Mayo JC, Sainz RM, Antolin I, Herrera F, Martin V, Reiter RJ: Regulation of antioxidant enzymes: a significant role for melatonin. $J$ Pineal Res 2004, 36:1-9.

10. Cuesta S, Kireev R, García C, Forman K, Escames G, Vara E, Tresquerres JA: Beneficial effect of melatonin treatment on inflammation, apoptosis and oxidative stress on pancreas of a senescence accelerated mice model. Mech Ageing Dev 2011, 132:573-582.

11. Cuesta S, Kireev R, Forman K, García C, Escames G, Ariznavarreta C, Vara E, Tresguerres JA: Melatonin improves inflammation processes in liver of senescence-accelerated prone male mice (SAMP8). Exp Gerontol 2010, 45:950-956.

12. Gitto E, Romeo C, Reiter RJ, Impellizzeri P, Pesce S, Basile M, Antonuccio P, Trimarchi G, Gentile C, Barberi I, Zuccarello B: Melatonin reduces oxidative stress in surgical neonates. J Pediatr Surg 2004, 39:184-189.

13. Hsu JT, Kuo CJ, Chen TH, Wang F, Lin CJ, Yeh TS, Hwang TL, Jan YY: Melatonin prevents hemorrhagic shock-induced liver injury in rats through an Akt-dependent HO-1 pathway. J Pineal Res 2012, 53(4):410416.

14. Verhaar MC, Stroes E, Rabelink TJ: Folates and cardiovascular disease. Arterioscler Thromb Vasc Biol 2002, 22:6-13.

15. Manzoor M, Runcie J: Folate-responsive neuropathy: report of 10 cases. $\mathrm{Br}$ Med J 1976, 1:1176-1178.

16. Daly LE, Kirke PN, Molloy A, Weir DG, Scott JM: Folate levels and neural tube defects.Implications for prevention. JAMA J Am Med Assoc 1995, 274:1698-1702.

17. Duthie SJ, Narayanan S, Brand GM, Pirie L, Grant G: Impact of folate deficiency on DNA stability. J Nutr 2002, 132:2444S-2449S.
18. Nakano E, Higgins JA, Powers HJ: Folate protects against oxidative modification of human LDL. Br J Nutr 2001, 86:637-639.

19. Moens AL, Champion HC, Claeys MJ, Tavazzi B, Kaminski PM, Wolin MS Borgonjon DJ, Van Nassauw L, Haile A, Zviman M, Bedja D, Wuyts FL, Elsaesser RS, Cos P, Gabrielson KL, Lazzarino G, Paolocci N, Timmermans JP Vrints CJ, Kass DA: High-dose folic acid pretreatment blunts cardiac dysfunction during ischemia coupled to maintenance of high-energy phosphates and reduces postreperfusion injury. Circulation 2008, 117:1810-1819.

20. Solini A, Santini E, Ferrannini E: Effect of short-term folic acid supplementation on insulin sensitivity and inflammatory markers in overweight subjects. Int J Obes (Lond) 2006, 30:1197-1202.

21. Rizzo P, Raffone E, Benedetto V: Effect of the treatment with myo-inositol plus folic acid plus melatonin in comparison with a treatment with myoinositol plus folic acid on oocyte quality and pregnancy outcome in IVF cycles, A prospective clinical trial. Eur Rev Med Pharmacol Sci 2010, 14:555-561.

22. Fournier I, Ploye F, Cottet-Emard JM, Brun J, Claustrat B: Folate deficiency alters melatonin secretion in rats. J Nutr 2002, 132:2781-2784.

23. Makni M, Chtourou Y, Fetoui H, Garouiel M, Boudawara T, Zeghal N: Evaluation of the antioxidant, anti-inflammatory and hepatoprotective properties of vanillin in carbon tetrachloride-treated rats. Eur J Pharmacol 2011, 668:133-139.

24. Malek FA, Möritz KU, Fanghänel J, Bienengräberc V: Reduction of procarbazine-induced cleft palates by prenatal folic acid supplementation in rats. Pathol Res Pract 2004, 200:33-40.

25. Okhawa H, Ohishi N, Yagi K: Assay for lipid peroxides in animal tissues by thiobarbituric acid reaction. Anal Biochem 1979, 95:351-358.

26. Moron MS, Depierre JW, Mannervik B: Levels of GSH, GR and GST activities in rat lung and liver. Biochim Biophys Acta 1979, 582:67-78.

27. Aebi H: Catalase in vitro. Method Enzymol 1984, 105:121-126.

28. Subramanian P, Mirunalini S, Pandi-Perumal SR, Trakht I, Cardinali DP: Melatonin treatment improves the antioxidant status and decreases lipid content in brain and liver of rats. Eur J Pharmacol 2007, 571:116-119.

29. Hwang SY, Siow YL, Au-Yeung KK, House JOK: Folic acid supplementation inhibits NADPH oxidase-mediated superoxide anion production in the kidney. Am J Physiol Renal Physiol 2010, 300:F189-F198.

30. Ebaid H, Salem A, Sayed A, Metwalli A: Whey protein enhances normal inflammatory responses during cutaneous wound healing in diabetic rats. Lipids Health Dis 2011, 10:235.

31. Basu S: Carbon tetrachloride-induced lipid peroxidation: eicosanoid formation and their regulation by antioxidant nutrients. Toxicology 2003 189:113-127.

32. Ramaiah SK, Rittling S: Role of osteopontin in regulating hepatic inflammatory responses and toxic liver injury. Expert Opin Drug Metab Toxicol 2007, 3:519-526.

33. Niemela O, Parkkila S, Yla-Herttuala S, Halsted C, Witztum JL, Lanca A, Israe $Y$ : Covalent protein adducts in the liver as a result of ethanol metabolism and lipid peroxidation. Lab Invest 1994, 70:537-546.

34. Reiter RJ: Melatonin: lowering the high price of free radicals. News Physiol Sci 2000, 15:246-250

35. Vitaglione P, Morisco F, Caporaso N, Fogliano V: Dietary antioxidant compounds and liver health. Crit Rev Food Sci Nutr 2004, 44:575-586.

36. Kadiska MB, Gladen BC, Baird DD, Dikalov AE, Sohal RS, Hatch GB, Jones DP, Mason RP, Barret JC: Biomarkers of oxidative stress study: are plasma antioxidants markers of CCl4 poisoning? J Free Rad Biol Med 2000, 28:838-845

37. Paulis L, Simko F: Blood pressure modulation and cardiovascular protection by melatonin: potential mechanisms behind. Physiol Res 2007 56:671-684.

38. Comporti M: Three models of free radical-induced cell injury. Chem Biol Interact 1989, 72:1-56

39. Lim Y, Levy M, Bray TM: Dietary zinc alters early inflammatory responses during cutaneous wound healing in weanling CD-1 mice. J Nutr 2004, 134:811-816.

40. Cheh N, Chipitsyna G, Gong Q, Yeo CJ: Arafat HA: Anti-inflammatory effects of the Nigella sativa seed extract, thymoquinone, in pancreatic cancer cells. HPB (Oxford) 2009, 11:373-381.

41. Bassiouny AR, Zaky A, Kandeel KM: Alteration of AP-endonuclease1 expression in curcumin-treated fibrotic rats. Ann Hepatol 2011, 10:516-530 
42. Mita A, Hashikura Y, Tagawa Y, Nakayama J, Kawakubo M, Miyagawa S: Expression of Fas ligand by hepatic macrophages in patients with fulminant hepatic failure. Am J Gastroenterol 2005, 100:2551-2559.

43. Zhang $L$, Wang $X$, Zheng $W$, Shi M: The effects of interleukin-10 on the expression of Fas and FasL in rat hepatic stellate cells. Med Chem 2006, 2:611-616.

44. Nagata S: Apoptosis by death factor. Cell 1997, 88:355-365.

45. Recknagel RO, Glende EA, Dolak JA, Waller RL: Mechanisms of carbon tetrachloride toxicity. Pharmacol. Therapeut. 1989, 43:139-154.

46. Kauffmann-Zeh A, Rodriguez-Viciana P, Ulrich E, Gilbert C, Coffer P, Downward J, Evan G: Suppression of c-Myc-induced apoptosis by Rassignalling through PI (3)K and PKB. Nature 1997, 385:44-548.

47. Huang FZ, Deng G, Liu XY, Luo CQ: Akt gene therapy for cirrhotic rats with portal hypertension. Zhong Nan Da XueXueBao Yi Xue Ban 2008, 33:31-37.

48. Ezell SA, Polytarchou C, Hatziapostolou M, Guo A, Sanidas I, Bihani T, Comb MJ, Sourvinos G, Tsichlis PN: The protein kinase Akt1 regulates the interferon response through phosphorylation of the transcriptional repressor EMSY. Proc Natl Acad Sci U S A 2012, 109:E613-E621.

49. Kaur S, Sassano A, Dolniak B, Joshi S, Majchrzak-Kita B, Baker DP, Hay N, Fish EN, Platanias LC: Role of the Akt pathway in mRNA translation of interferon-stimulated genes. Proc Natl Acad Sci U S A 2008, 105:4808-4813.

50. Kane $L P$, Andres PG, Howland KC, Abbas AK, Weiss A: Akt provides the CD28 costimulatory signal for up-regulation of IL-2 and IFN-gamma but not TH2 cytokines. Nat Immunol 2001, 2:37-44.

51. Chan TY, Tang PL: Effect of melatonin on the maintenance of cholesterol homeostasis in the rat. Endocrinol. Res. 1995, 21:681-696.

52. Muller-Wieland D, Behnke B, Koopmann K, Krone W: Melatonin inhibits LDL receptor activity and cholesterol synthesis in freshly isolated human mononuclear leucocytes. Biochem Biophys Res Commun 1994, 202:416-421.

53. Dietschy JM: Theoretical considerations of what regulates low-density lipoprotein and high-density lipoprotein cholesterol. Am J Clin Nutr 1997, 65:1581S-1589S

54. Marucci L, Alpini G, Glaser SS, Alvaro D, Benedetti A, Francis H, Phinizy JL, Marzioni M, Mauldin J, Venter J, Baumann B, Ugili L, LeSage G: Measurement of catalytic levels of enzymes. Part2. IFCC method for aspartate aminotransferase. J Clin Chem Clin Biochem 2002, 24:497-510

55. Gomez TS, Hamann MJ, McCarney S, Savoy DN, Lubking CM, Heldebrant MP, Labno CM, McKean DJ, McNiven MA, Burkhardt JK, Billadeau DD: Dynamin 2 regulates $T$ cell activation by controlling actin polymerization at the immunological synapse. Nat Immunol 2005, 6:261-270.

56. Fuse S, Zhang W, Usherwood EJ: Control of memory CD8+ T cell differentiation by CD80/CD86-CD28 costimulation and restoration by IL-2 during the recall response. J Immunol 2008, 180:1148-1157.

\section{doi:10.1186/1743-7075-10-20}

Cite this article as: Ebaid et al:: Folic acid and melatonin ameliorate carbon tetrachloride-induced hepatic injury, oxidative stress and inflammation in rats. Nutrition \& Metabolism 2013 10:20.

\section{Submit your next manuscript to BioMed Central and take full advantage of:}

- Convenient online submission

- Thorough peer review

- No space constraints or color figure charges

- Immediate publication on acceptance

- Inclusion in PubMed, CAS, Scopus and Google Scholar

- Research which is freely available for redistribution 